\title{
Susceptibility and Detection of Extended Spectrum $\beta$-Lactamase Enzymes from Otitis Media Pathogens
}

\author{
${ }^{1}$ Ejikeugwu Chika, ${ }^{2}$ Iroha Ifeanyichukwu, ${ }^{1}$ Adikwu Michael and ${ }^{1}$ Esimone Charles \\ ${ }^{1}$ Department of Pharmaceutical Microbiology and Biotechnology, \\ Faculty of Pharmaceutical Sciences, \\ Nnamdi Azikiwe University, P.M.B 5025, Awka, Nigeria \\ ${ }^{2}$ Department of Applied Microbiology, \\ Faculty of Biological Sciences \\ Ebonyi State University, P.M.B 053, Abakaliki, Nigeria
}

Received 2012-12-28, Revised 2013-03-15; Accepted 2013-05-21

\begin{abstract}
Otitis media is the bacterial infection of the middle ear usually accompanied with inflammation, effusions and pain. It can present clinically in two major forms: Acute Otitis Media (AOM) and Otitis Media with Effusion (OME) and it is one of the leading cause of hospital visits and antibiotic prescriptions amongst children and even adults. Antibiotic resistance is a global public health problem and Extended Spectrum $\beta$-Lactamase (ESBL) enzymes is one of the new mechanisms of resistance in especially Gram negative bacteria including Escherichia coli, Klebsiella pneumoniae and Pseudomonas aeruginosa. ESBLs are plasmid-mediated $\beta$ lactamase enzymes that hydrolyze extended-spectrum oxyimino 3rd generation cephalosporins and monobactams. Organisms producing ESBLs have remained important nosocomial and community-acquired pathogens over the years. Ear swab specimens of children (aged 0-7) with suspected Otitis media infections and who attended a tertiary hospital in Enugu, Nigeria were cultured on growth media. E. coli, K. pneumoniae and $P$. aeruginosa were isolated and identified by standard microbiological techniques. Antibiogram was conducted on all isolated ear pathogens by Kirby-Bauer disk diffusion method and ESBL production was evaluated by the Double Disk Synergy Test (DDST) method. Imipenem and meropenem were the most active antibiotics against the E. coli, K. pneumoniae and P. aeruginosa ear pathogens. Sulphamethoxazoletrimethoprim was the least active agent against the tested ear pathogens and this was followed by ofloxacin, ciprofloxacin, gentamicin, cefotaxime and ceftazidime. None of the E. coli, K. pneumoniae and P. aeruginosa ear pathogens produced ESBLs by the method used. ESBL production by pathogenic bacteria confers on organisms the ability to be multidrug resistant. Their prompt and accurate detection from clinical specimens, together with reporting them along with hospitals routine antibiogram results is vital as this will help to guide therapy and forestall any treatment failure in the face of an ESBL infection.
\end{abstract}

Keywords: ESBLs, Antibiotic Resistance, Ear Swabs, Gram Negative Bacteria

\section{INTRODUCTION}

Otitis media is the infection of the middle ear by pathogenic microorganism's including Streptococcus pneumoniae, staphylococcus aureus, Pseudomonas spp. and the Enterobacteriaceae which are either resident or transported to the middle ear by insufflations of the lower respiratory tract system through the eustachian Microbiology and Biotechnology, Faculty of Pharmaceutical Sciences, Nnamdi Azikiwe University, P.M.B 5025, Awka, Nigeria 
tube (Akinjogunla and Eghafona, 2012). It is the most common infection amongst young children of school age and to lesser extent adults alike and it is also the reason for which antibiotics are prescribed for children in hospitals across the world (Monasta et al., 2012; Morris and Leach, 2009). According to Akinjogunla and Eghafona (2012), there are two types of middle ear infection: Chronic Otitis Media (COM) and Acute Otitis Media (AOM). Otitis media infection (which is an example of upper respiratory tract infection) affects mostly children at a very early age (e.g., 0-10 years) and it is usually mild but in most severe cases, therapy using antibiotic is the only option to remedy the situation. Middle ear infections (which can either be with or without effusions) usually presents with ear mucosal changes and otorrhoea (i.e., discharge from the middle ear), difficulty in hearing, irritability, otalgia (ear pain) and fever amongst other signs and symptoms (WHO, 2004). Antibiotic prescription protocols in Otitis media infection can be a predisposing factor for the prevalence of resistant strains of bacteria (especially those that produce extended spectrum $\beta$-lactamase enzymes) amongst infected patients. Bacterial resistance to some readily available drugs, which is already a global health menace, is primarily fuelled by prior antibiotic usage (especially irrationally). Extended Spectrum $\beta$ Lactamase (ESBL) enzymes are plasmid mediated $\beta$ lactamases that hydrolyze and confer on pathogenic bacteria the exceptional ability to be resistant to oxyimino 3rd generation cephalosporins (Kaye et al., 2004; Schmitt et al., 2007). ESBLs which were first discovered in Germany in 1983 in strains of Klebsiella spp are commonly seen in Escherichia coli and Klebsiella spp., but they are also prevalent in other members of the Enterobacteriaceae and in some nonEnterobacteriaceae e.g., Pseudomonas aeruginosa and Acinetobacter baumannii (Rubtsova et al., 2010). Pathogens expressing ESBLs arise by mutations in genes for earlier/common plasmid mediated $\beta$ lactamases (e.g., TEM and SHV) and they are inhibited by $\beta$-lactamase inhibitors such as clavulanic acid (Bradford, 2001; Rubtsova et al., 2010; Ramphal and Ambrose, 2004). Risk factors for ESBL acquisition includes prior antibiotic usage (3rd generation cephalosporins), long hospitalization, surgical exposure, use of urine catheter, transfer from one hospital to another and exposure to hospital pathogens (Rubtsova et al., 2010). Failure to detect pathogenic bacteria producing ESBLs in both the community and hospital settings is detrimental because it poses a higher risk of treatment failure in the patients since organisms producing ESBLs are usually resistant to a wide variety of $\beta$-lactams especially the oxyimino $3 \mathrm{rd}$ generation cephalosporins including some non- $\beta$-lactams. Due to the global threat of antibiotic resistance in hospitals across the globe and the need to accurately detect, report and contain them, the current study is aimed at evaluating the susceptibility profile of some ear pathogens and to also investigate the occurrence of ESBL producing bacterial pathogens in Otitis media patients from a tertiary hospital in Enugu, southeast Nigeria.

\section{MATERIALS AND METHODS}

\subsection{Sample Collection}

Ear swab specimens were collected using sterile swab-sticks from children with suspected cases of Otitis media infections without effusions and between the ages of 0-7 years old who attended the Ear, Nose and Throat (ENT) Department of a tertiary hospital in Enugu state, Nigeria. Specimens from individuals without any history or form of middle-ear infections were used as negative control.

\subsection{Isolation and Identification of Pathogens}

Eighty (80) ear swabs were examined directly under the microscope; Gram stained and cultured on Blood Agar (BA), Mac Conkey Agar (MAC) and chocolate agar plates and incubated at $37^{\circ} \mathrm{C}$ overnight. Plates of chocolate agar were incubated anaerobically for $48 \mathrm{~h}$ at $37^{\circ} \mathrm{C}$ in an anaerobic jar. Suspect isolates were subcultured and identified using standard conventional microbiological techniques (Cheesbrough, 2000; Vandepitte et al., 2003).

\subsection{Susceptibility Testing and Screening for ESBL Production}

The antibiogram of the clinical isolates (adjusted to 0.5 McFarland turbidity standards) was first evaluated on Mueller-Hinton $(\mathrm{MH})$ agar plates by the Kirby-Bauer disk diffusion method using $\beta$-lactam and non- $\beta$-lactam single antibiotic disks of Sulphamethoxazoletrimethoprim $(25 \mu \mathrm{g})$, ceftazidime $(30 \mu \mathrm{g})$, cefotaxime (30 $\mu \mathrm{g})$, gentamicin $(10 \mu \mathrm{g})$, imipenem $(10 \mu \mathrm{g})$, meropenem $(10 \mu \mathrm{g})$, ciprofloxacin $(5 \mu \mathrm{g})$ and ofloxacin $(5 \mu \mathrm{g})$ (Oxoid, UK). Isolates that showed reduced susceptibility to any of the indicated cephalosporins using ESBL screening breakpoints (ceftazidime $\leq 22$ and cefotaxime $\leq 27$ ) was 
considered possible ESBL producer that warrants a phenotypic ESBL confirmation test (Umadevi et al., 2011; Girlich et al., 2007). Escherichia coli ATCC 25922, Klebsiella pneumoniae ATCC 700603 and Pseudomonas aeruginosa ATCC 27853 were used as control strains. Susceptibility studies and ESBL screening was determined in line with the Clinical Laboratory Standard Institute (CLSI) guidelines (Bradford, 2001; Wikler, 2005).

\subsection{Detection of Extended Spectrum $\beta$ - Lactamase (ESBL) Enzymes}

ESBL production was confirmed by the Double Disk Synergy Test (DDST) method. Briefly, overnight suspension of the test bacteria adjusted to 0.5 McFarland turbidity standards was swabbed aseptically on a $\mathrm{MH}$ agar (Oxoid, UK). A combination disk of amoxicillin-clavulanic acid, AMC $(20 / 10 \mu \mathrm{g})$ was placed at the center of the $\mathrm{MH}$ agar plate and cefotaxime $(30 \mu \mathrm{g})$ and ceftazidime $(30 \mu \mathrm{g})$ were placed on either sides of the central disk (AMC-20/10 $\mu \mathrm{g}$ ) at a distance of $15 \mathrm{~mm}$. The plates were incubated for $18-24 \mathrm{~h}$ at $37^{\circ} \mathrm{C}$. After incubation, $\mathrm{a} \geq 5 \mathrm{~mm}$ increase in zone diameter for either of the cephalosporins (CAZ and CTX) tested in combination with AMC $(20 / 10 \mu \mathrm{g})$ compared to its zone when tested alone confirms ESBL production in the test bacterium phenotypically (King-Ting et al., 2009).

\section{RESULTS}

A total of 80 ear swabs were analyzed microbiologically (from the period of April 2011 to December 2011) in the present day study. The age groups of the children were represented as follows: 0-1 years, 2-3 years, 4-5 years and 6-7 years. Fifty seven Gram negative ear pathogens that were of clinical importance were successfully isolated. Out of the 57 ear pathogens, 26 isolates were from males while 31 were from females.

The age and gender distribution of patient's ear swabs and the isolated pathogens are shown in Table 1.

The susceptibility of the ear pathogens was evaluated using 8 batteries of single antibiotic disks including: Sulphamethoxazole-trimethoprim $(25 \mu \mathrm{g})$, ceftazidime (30 $\mu \mathrm{g})$, cefotaxime $(30 \mu \mathrm{g})$, gentamicin $(10 \mu \mathrm{g})$, imipenem $(10 \mu \mathrm{g})$, meropenem $(10 \mu \mathrm{g})$, ciprofloxacin $(5$ $\mu \mathrm{g})$ and ofloxacin $(5 \mu \mathrm{g})$. The percentage susceptibility of the E. coli, K. pneumoniae and $P$. aeruginosa clinical isolates from the ear swabs are depicted in Fig. 1.

The occurrence of ESBL production in the ear pathogens (E. coli, K. pneumoniae and $P$. aeruginosa) was determined by the double disk synergy test method in line with the Clinical Laboratory Standard Institute (CLSI) guidelines and the results are as shown in Table 2.

Table 2 shows the frequency of ESBL production from the isolated pathogens.

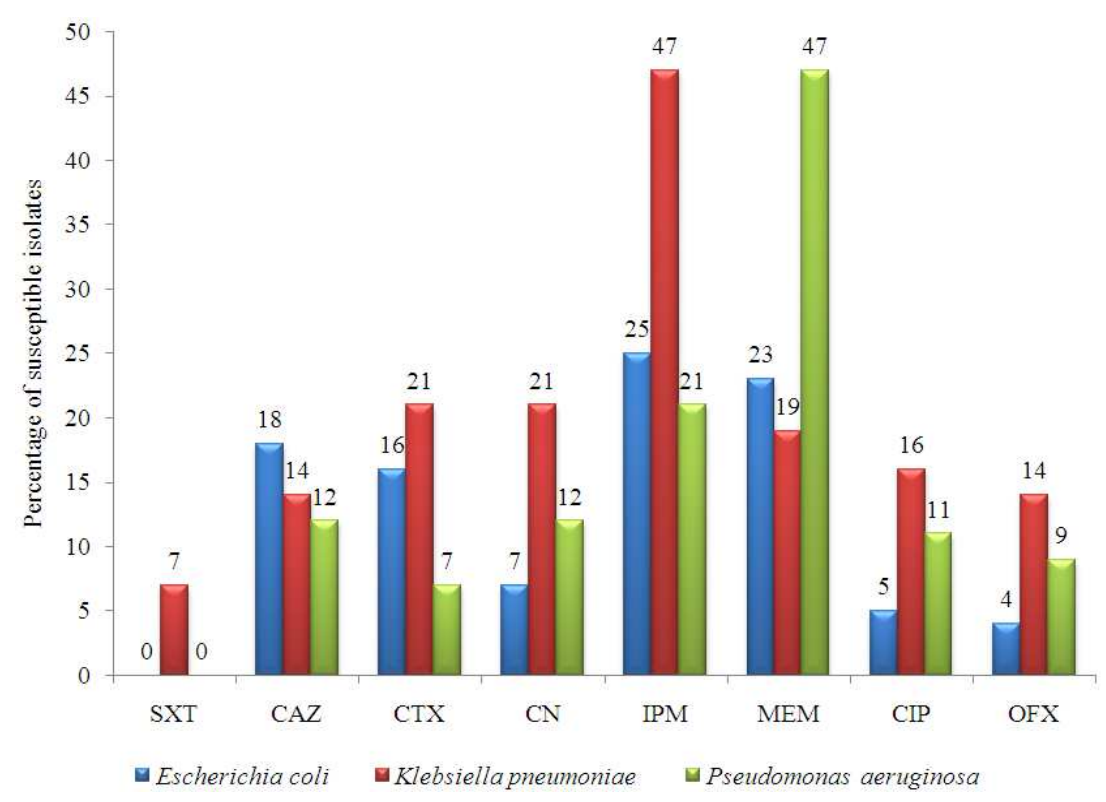

Fig. 1. Percentage susceptibility of the bacterial isolates to various antibiotics. SXT-Sulphamethoxazole-Trimethoprim, CAZCeftazidime, CTX-Cefotaxime, CN-gentamicin, IPM-IMIPENEM, MEM-Meropenem, CIP-Ciprofloxacin and OFX-Ofloxacin 
Table 1. Age and gender distribution of patients and isolates

\begin{tabular}{lc}
\hline Age (years) & Isolates (no.) \\
\hline $0-1$ & 17 \\
$2-3$ & 17 \\
$4-5$ & 32 \\
$6-7$ & 7 \\
Total & 57 \\
Gender & \\
Males & 26 \\
Females & 31 \\
Total & 57 \\
Organisms & \\
Pseudomonas aeruginosa & 11 \\
Klebsiella pneumoniae & 30 \\
Escherichia coli & 16 \\
Total & 57 \\
\hline
\end{tabular}

Table 2. Distribution of ESBL production

\begin{tabular}{llc}
\hline Isolate (No.) & ESBL & $\begin{array}{l}\text { ESBL } \\
\text { negative (No.) }\end{array}$ \\
\hline Escherichia coli & None & All \\
Pseudomonas aeruginosa & None & All \\
Klebsiella pneumoniae & None & All \\
Total & None & 57 \\
\hline
\end{tabular}

\section{DISCUSSION}

The ability to contain the emergence and spread of drug resistance pathogens including those that produce ESBLs is largely dependent on the prompt and accurate detection of these enzymes by the clinical microbiology laboratory. Bacterial pathogens producing Extended Spectrum $\beta$-Lactamases (ESBLs) and other high-grade $\beta$-lactamases are a source of worry to both patients and clinicians alike and they have rendered a variety of antibiotics inefficacious due to their multidrug resistant nature. According to Souha and Zeina (2011), the production of $\beta$-lactamase enzymes by bacterial pathogens is one of the most commonly encountered forms of resistance to the $\beta$-lactams and, Gram negative bacteria producing these enzymes are tough adversaries to clinicians, microbiologists and researchers alike (Souha and Zeina, 2011). The selection of this mechanism of resistance called ESBL is an indication of antibiotic consumption (especially irrationally) in both the community and hospital settings and this is especially with regards to the cephalosporins (Bradford, 2001). According to studies, the use of antibiotics especially irrationally is the reason there is for the emergence and spread of resistant strains of pathogens that are of clinical importance in both the community and hospital environments (Bradford, 2001; Schmitt et al., 2007). The treatment of Otitis media infections in children is gradually being compromised and complicated by the rising resistance of some common ear pathogens to some readily available antibiotics, thus the need for a consistent and up to date monitoring of the susceptibility profiles of bacterial pathogens to these prescribed antibiotics.

In the present day study, all 57 ear pathogens (E. coli, $K$. pneumoniae and $P$. aeruginosa) were subjected to 8 batteries of single antibiotic disks including: SXTSulphamethoxazole-trimethoprim, CAZ-ceftazidime, CTX-cefotaxime, CN-gentamicin, IPM-imipenem, MEMmeropenem, CIP-ciprofloxacin and OFX-ofloxacin in order to determine their susceptibility patterns. The carbapenems (imipenem and meropenem) were the most active agents against the tested ear pathogens as IPM showed a percentage susceptibility of 25,47 and $21 \%$ against $E$. coli, $K$. pneumoniae and $P$. aeruginosa ear pathogens respectively. MEM was active against 23, 19 and $47 \%$ E. coli, K. pneumoniae and P. aeruginosa ear pathogens respectively. Surprisingly, none of the E. coli and $P$. aeruginosa isolates showed any form of susceptibility to SXT and SXT was the least active agent tested showing only $7 \%$ susceptibility on K. pneumoniae isolates. For the cephalosporins, ceftazidime showed 18, 14 and $12 \%$ susceptibility on E. coli, K. pneumoniae and $P$. aeruginosa isolates respectively while cefotaxime showed percentage susceptibility of 16,21 and $7 \%$ on $E$. coli, K. pneumoniae and P. aeruginosa isolates respectively. Gentamicin $(\mathrm{CN})$, an amino glycoside showed percentage susceptibility of 7, 21 and $12 \%$ on $E$. coli, K. pneumoniae and $P$. aeruginosa isolates respectively. For the fluoroquinolones (ciprofloxacin and ofloxacin), a percentage susceptibility of 5, 16, 11 and 4, 14, 9\% was observed for CIP and OFX respectively against the E. coli, $K$. pneumoniae and $P$. aeruginosa ear pathogens.

A report from southeast Nigeria on the susceptibility of some bacteria from both human and sewage sources to a variety of antibiotics including SXT-Sulphamethoxazoletrimethoprim, CAZ-ceftazidime, CTX-cefotaxime, CNgentamicin, CIP-ciprofloxacin and OFX-ofloxacin showed that $K$. pneumoniae, E. coli and $P$. aeruginosa isolates were highly resistant to the tested drugs especially SXT, CN and OFX (Eze, 2012), a result similar to ours.

In a similar study conducted in south-south Nigeria by Akinjogunla and Eghafona (2012), K. pneumoniae, E. coli and $P$. aeruginosa isolates were highly susceptible to imipenem and ciprofloxacin and these were least susceptible to cefotaxime, a cephalosporin (Akinjogunla and Eghafona, 2012).

Surprisingly, we observed that there was a zero ESBL production by the K. pneumoniae, E. coli and $P$. aeruginosa ear pathogens. 
This result however, is in sharp contrast to a similar study conducted by Akinjogunla and Eghafona (2012) which detected ESBL production in 33 ear pathogens out of 81 Gram negative bacilli from suspected cases of Otitis media here in Nigeria (Akinjogunla and Eghafona, 2012). Reports of ESBL production by ear pathogens in Nigeria is scarce, but the zero production of ESBLs by the $K$. pneumoniae, $E$. coli and $P$. aeruginosa ear pathogens in our study by the double disk synergy test method is the first (especially in the southeast Nigeria where this study was carried out) and this does not call for relaxation in the lookout for these enzymes and others that ravage our therapeutic armamentarium. It is very important that hospitals in this part of the world take the problem of ESBLs very seriously because only then can they forestall any outbreak due to them. More holistic and molecular studies are required to establish the prevalence of ESBL production amongst children with Otitis media infection in this part of the world. Microbiology laboratories in our hospitals in this part of the world should test suspicious pathogens for ESBL production and report same in line with their routine susceptibility results as this will go a long way in guiding therapy and ensuring that patients prognosis of healing after treatment are guaranteed.

\section{CONCLUSION}

The $K$. pneumoniae, E. coli and $P$. aeruginosa ear pathogens were found to be highly susceptible to the carbapenems (imipenem and meropenem) while Sulphamethoxazole-trimethoprim, an antimetabolite showed no activity against $E$. coli and $P$. aeruginosa isolates. Our study also reveals a zero ESBL production by the $K$. pneumoniae, E. coli and P. aeruginosa ear pathogens. Extended Spectrum $\beta$-Lactamase (ESBL) production by pathogenic bacteria is one of the mechanisms used by these organisms to evade the onslaught of antimicrobial agents. The prompt and accurate detection of pathogens producing ESBLs from clinical specimens of patients across Nigerian hospitals as a routine is urgently needed in order to prevent their emergence and spread. Since Otitis media infection does not always require antibiotic treatment, prescription of drugs in cases of middle ear infection should be done with caution so as to avert the emergence and spread of resistant strains of bacteria in the hospital and community settings.

\section{REFERENCES}

Akinjogunla, O.J. and N.O. Eghafona, 2012. Mycological investigation in patients with acute Otitis media. Sci. J. Microbiol., 1: 19-26.
Bradford, P.A., 2001. Extended-spectrum $\beta$-lactamases in the 21st century: Characterization, epidemiology and detection of this important resistance threat. Clin. Microbiol. Rev., 14: 933-951. DOI: 10.1128/CMR.14.4.933-951.2001

Cheesbrough, M., 2000. Biochemical Tests to Identify Bacteria. In: District Laboratory Practice in Tropical Countries, Cheesbrough, M., (Ed.), Cambridge University Press, UK., ISBN-10: 0521665450, pp: $178-187$.

Eze, E.A., 2012. Systematic variations in drug resistance among some enteric gram-negative bacilli isolated from humans and sewage. J. Microbiol. Antimicrobials, 4: 6-5. DOI: 10.5897/JMA11.031

Girlich, D., L. Poirel, A. Carattoli, I. Kempf and M.F. Lartigue et al., 2007. Extended-spectrum $\beta$ lactamase CTX-M-1 in Escherichia coli isolates from healthy poultry in France. Applied Environ. Microbiol., 73: 4681-4685. DOI: 10.1128/AEM.02491-06

Kaye, K.S., J.J. Engemann, H.S. Fraimow and E. Abrutyn, 2004. Pathogens resistant to antimicrobial agents: epidemiology, molecular mechanisms and clinical management. Infect. Dis. Clin. N. Am., 18: 467-511. DOI: 10.1016/j.idc.2004.04.003

King-Ting, L., Y. Rohani, Y. Chew-Chieng, P. Savithri and T. Kwai-Lin, 2009. Characterization of multidrug resistant Esbl-producing Escherichia coli isolates from hospitals in Malaysia. J. Biomed. Biotechnol., 2009: 1-10. DOI: 10.1155/2009/165637

Monasta, L., L. Ronfani, F. Marchetti, M. Montico and L.V. Brumatti et al., 2012. Burden of disease caused by Otitis media: Systematic review and global estimates. PLos ONE., 7: 36226-36226. DOI: 10.1371/journal.pone.0036226

Morris, P.S and A.J Leach, 2009. Acute and chronic Otitis media. Pediatr Clin. N. Am., 56: 1383-1399. DOI: $10.1016 /$ j.pcl.2009.09.007

Ramphal, R. and P.G. Ambrose, 2004. Extendedspectrum $\beta$-lactamases and clinical outcomes: Current data. Clin. Infect. Dis., 2: S164-S172. DOI: $10.1086 / 500663$

Rubtsova, M., M.M. Yu., T.T. Ulyashova, R.D. Bachmann and A.M. Egorov, 2010. Multiparametric determination of genes and their point mutations for identification of beta-lactamases. Biochem. (Mosc)., 75: 1628-1649. DOI: 10.1134/S0006297910130080

Schmitt, J., E. Jacobs and H. Schmidtt, 2007. Molecular Characterization of extended-spectrum betalactamases in Enterobacteriaceae from patients of two hospitals in Saxony, Germany. J. Med. Microbiol., 56: 241-249. DOI: 10.1099/jmm.0.46670-0 
Souha, S.K. and A.K. Zeina, 2011. Current concepts in antimicrobial therapy against resistant gramnegative organisms: Extended-Spectrum $\beta$ Lactamase-producing Enterobacteriaceae, carbapenem-resistant Enterobacteriaceae and multidrug-resistant pseudomonas aeruginosa. Mayo. Clin. Proc., 86: 250-259. DOI: 10.4065/mcp. 2010.0674

Umadevi, S., G. Kandhakumari, N.M. Joseph, S. Kumar and J.M. Easow et al., 2011. Prevalence and antimicrobial susceptibility pattern of ESBL producing Gram negative bacilli. J. Clin. Diagnostic Res., 5: 236-239.
Vandepitte, J., J. Verhaegen, K. Engbaek, P. Rohner and P. Piot et al., 2003. Bacteriological Investigations. In: Basic Laboratory Procedures in Clinical Bacteriology, Engbaek, K., C.C. Heuck, P. Piot, P. Rohner and J. Vandepitte (Eds.), WHO, Geneva, Switzerland, ISBN-10: 9241545453 , pp: 20-74.

WHO, 2004. Chronic suppurative otitis media: burden of illness and management options. Edith Cowan University.

Wikler, M.A., 2005. Performance Standards for Antimicrobial Susceptibility Testing: Fifteenth Informational Supplement. 15th Edn., Clinical and Laboratory Standards Institute, ISBN-10: 1562385569, pp: 167. 